Cambridge Archaeological Journal

http://journals.cambridge.org/CAJ

Additional services for Cambridge Archaeological Journal:

ARCHAEOLOGICAL.

Email alerts: $\underline{\text { Click here }}$

Subscriptions: $\underline{\text { Click here }}$

Commercial reprints: Click here

Terms of use : Click here

\title{
Mind and Body in Landscape Research
}

Christopher Tilley

Cambridge Archaeological Journal / Volume 14 / Issue 01 / April 2004, pp 77 - 80

DOI: 10.1017/S0959774304240057, Published online: 02 June 2004

Link to this article: http://journals.cambridge.org/abstract_S0959774304240057

How to cite this article:

Christopher Tilley (2004). Mind and Body in Landscape Research. Cambridge Archaeological Journal,14, pp 77-80 doi:10.1017/ S0959774304240057

Request Permissions : $\underline{\text { Click here }}$ 


\section{Viewpoint}

\section{Can Archaeology Recover Past Intentions?}

The issue of intentionality lies at the heart of most archaeological interpretation. In the course of excavation or analysis we uncover the traces of sequences of human actions that we then proceed to interpret in terms of an original form or an original purpose or meaning that lay inside the minds of prehistoric or early historic individuals.

To take a very simple example, we see a polished stone axe as an intentional end-product, and an axe rough-out as evidence of an arrested process, on the assumption (perhaps quite a reasonable one) that the desired objective was in each case to produce a polished stone axe. Many of those abandoned at the rough-out stage are interpreted by archaeologists who look for imperfections in the raw material or other blemishes - which again assumes a particular intentionality - that the makers would have completed the work if only some such factor had not come to dissuade them. The problem of 'intended' form underlies (and indeed threatens to undermine) many typological approaches in archaeology; at the very least it questions whether the patterning that we see corresponds to some desired and intended end-product. It is easy to assume that Palaeolithic flint-knappers had in mind the image of an end-scraper or a backed knife when they set about their task, but is this borne out by ethnography?

Such ambiguities are not restricted to artefacts but apply also to settlement, economy and symbolic or ritual behaviour. Were prehistoric burial mounds designed as finished wholes and built stage by stage, by successive generations, according to a preconceived plan? Or were they constantly in process of modification and redescription? Can we distinguish sacred spaces from profane? Can we determine whether particular effects were intended or were merely chance by-products; the acoustics of enclosed spaces such as burial chambers pose particular challenges of interpretation. Rock art may appear to depict animals such as deer or boar: but are these real, living animals or are they mythical or symbolic beings?

The concern with the built and the made extends into the wider prehistoric landscape when we consider the meanings traditionally attached to rivers, lakes or mountains. These are sometimes materialized (or at least hinted at) through special practices of deposition or though the carving or painting of images at sacred locations. This may lead us to suppose that particular places in the landscape held a special significance, but can or should we seek to go further, and suggest what meaning or meanings were attached to them?

The contributions to this Viewpoint consider issues of intentionality across a range of archaeological contexts, from lithics to landscape. There are no simple answers, but a careful reading of patterning and innovation may allow informed insights into the ways in which past individuals interacted knowledgeably and intentionally with their surroundings and with each other. 


\section{Mind and Body in Landscape Research}

\section{Christopher Tilley}

'Don't you find it all a bit depressing in the end? You'll never really know what was going on' (student comment)

Intentionality would seem to be the fundamental concept in all prehistoric landscape research. We want to know the reasons why people chose to settle in one place or another, built particular types of monuments where they did, how they moved around the landscape, procured, exchanged and consumed material and non-material resources, deposited artefacts, etc. If, then, we are hoping to interpret the patterns we perceive in the landscape in terms of intentions or reasons, archaeological research becomes inevitably cognitive in nature: we all have to be mind-readers.

From a traditional perspective, understanding the nature of prehistoric minds supposedly provides the key to interpreting material culture because the latter is a product of the former. We have to try and reconstruct the way people thought about the landscape in order to understand the manner in which they lived in it. Reconstructions of these prehistoric

CAJ 14:1, 77-80 $\quad$ (c) 2004 McDonald Institute for Archaeological Research DOI: 10.1017 / S0959774304240057 Printed in the United Kingdom 
mind-sets in the literature - usually implicit, because particular types of cognitive processes are rarely discussed - currently range between the extremes of a utilitarian logic of practicality and functionalist efficency, and a symbolic logic without any apparent constraint apart from, perhaps, its own internal coherence. Landscapes and environments either more or less determine what people do or they are blank slates in which anything becomes possible.

Yet whatever kind of logic we infer we're all bad mind-readers at the end of the day. Almost all statements in archaeological publications are replete with standard qualifications, the words: 'perhaps', 'possibly', 'could be', 'might be' fill our texts simply because the one thing that we can be certain about is that we can't think like prehistoric people and can never know their minds.

This, of course, is only the tip of the interpretive iceberg. Besides people having intentions or reasons for their actions we may need to consider differences between individual intentions and collective intentions. Then there are the unintended consequences, or outcomes of actions, which need to be taken into account, differences between the reasons behind making something and how it is received and understood by others. Furthermore, differences between discursive consciousness and practical, routinized or 'habitual' thought may be important. A classic understanding in anthropological research is that people frequently say one thing and do another. The reasons for their actions may typically be rationalized afterwards and therefore do not provide a reliable guide anyway to understanding why they have acted in one way or another. Fortunately this is not a problem for archaeologists as the archaeological record is the outcome of actual practice. Nevertheless, unacknowledged reasons or intentions are often fundamental: people may not be fully aware themselves of what they are doing and why. So the intentions an archaeologist might reconstruct would often not be the same as those which might have been held by prehistoric agents if we could only interview them. To cap it all, intentions or reasons for actions are rarely simple and singular. They are often complex and multiple and change through time.

Consequently there is never likely to be one way to understand landscapes in terms of intentions, but many. It becomes a multiple field of interpretive possibilities, a dialogue between the archaeologist and the material remains of practice. The only reason to be depressed about this is if we are striving for certainty. But that is not the name of the game in any social science. Just as we can't read past minds, we can't read those in the present either. Whether we can even understand our own individual minds adequately is inherently problematic. We try to make sense of the material with which we work, explore interpretive possibilities which may throw more, or less light, on that which we seek to understand.

Material culture bears meaning and, because it has meaning, a recourse to mind in terms of seeking reasons or intentions for its production seems almost inevitable, bringing with it all the kinds of considerations mentioned above. Fieldwork in landscape archaeology crucially depends on the assignment of intentionality. The art of being able to make the statement 'this is a round barrow', 'this is a megalithic tomb', as opposed to a natural undulation or rock in the land surface, instantly makes a place meaningful for us. Then we can ask: why is it there? and what was it for? We do not ask such questions with regard to natural features. This culture/nature distinction, however, is in many ways problematic. A hill or a rock formation which nobody has made can, of course, be as meaningful as the round barrow or the megalith and sometimes more so. Consequently we need to uncouple the concepts of meaning and intentionality. The former is always assigned, the latter occurs because of human involvement. One of the problems of landscape research until recently has been a failure to do this so that the significance of 'natural' places for human settlement and land use have typically been downplayed or ignored.

Meaning may, in principle, reside anywhere in a landscape. Intentionality, by contrast, is fixed in it through human action, but both are invested in specific places. By investigating the relationship between natural places and cultural places in the landscape we can hope for a fuller and more nuanced interpretation. In doing so, an interpretive stress on mind in terms of intentions and reasons becomes radically altered. We do not require these concepts when investigating the potential significance of hills or stones but we are, of course, still interested in the manner in which people may have thought about and related to these places. This is a question of perception.

The traditional view of perception is that it flows from the mind. We are therefore dealing solely with cognitive processes. An alternative phenomenological view suggests that perception flows from the mind in the body. In other words, the manner in which humans perceive the world is intimately bound up with the kinds of bodies we all have, and in a basic sense, share. We see the world in and through the fleshiness of our bodies: perception is embodied. Now this perspective moves us away from 
a focus on intentionality and meaning as traditionally understood and in the manner discussed so far. We do not just interpret with our minds in a distanciated way, but through our sensing bodies. The body, in effect, becomes a primary research tool. We understand landscape not just through thinking about it, employing concepts of meaning and intentionality but through feeling it, through being there: the significance of the stone or the hill as experienced through the body. The logical outcome of this perspective is to call radically into question all forms of landscape research which are purely cognitive and attempt to reconstruct reasons or intentions without relating these to the physicality of bodily experience, at rest or in movement, in the landscape itself.

There is a further and more radical consequence of this stress on the embodied nature of experience: the need to call into question a distinction between persons with their minds and intentions, or reasons, and stones and hills and megaliths and barrows without any of these. A notion of intentionality has always been the key attribute of agency. It creates the familiar distinction between active subjects who think and passive objects that are inert and may have meanings ascribed to them or not. However, natural features of the landscape have effects on people as do cultural products. They may constrain or determine how one may move and what one perceives. In this sense they possess agency without thought or intentionality: they are more like subjects than objects (Tilley 1999). The power of this agency has profound effects on the manner in which we experience them and think them through our bodies. Landscape research then becomes the art of describing and discussing what kinds of effects natural features and cultural monuments have on us through our bodily experience of them. Quite crucially this leads to a redefinition of meaning in which we move away from considering it simply in traditional cognitive terms and linking it with a notion of intentionality. In other words we can discuss the bodily effects of landscapes: how landscapes come to be meaningful; and uncouple this question from what these landscapes meant. We can suggest reasons why the position of a natural stone or the location of a barrow was significant without necessarily having to translate this further into specific statements such as: 'it was significant because it may have represented a founding ancestor'.

I will try to illustrate this point by referring to an ongoing study of rock art in the landscape (see Tilley 2004, ch. 4; Tilley n.d.). While rock art typically occurs on 'natural' stones in landscape settings most work has ignored both. The study of rock art has always been dominated by the attempt to interpret the specific images. On one level this is simply about denotative meaning: is it a horse or a deer, a boat or a sledge? Then we move on to questions of connotative meaning and almost automatically want to know: what does this representation symbolize? What was its significance in the mind of the person who carved it? We go straight back to all the problems of trying to grapple with intentionality and meaning discussed above. We may get depressed and give up altogether, or simply write the images off in some way according to a standard rote formula, e.g. as yet another example of so-called 'entoptic phenomena,' or seek another kind of solace in the acts of documentation, and counting and measuring the images.

The alternative to this is to investigate: 1 ) the relationship between the images and the form and character of the rocks on which they occur; 2) the landscape settings and relationships between these rocks; and 3) the manner in which the carved panels and the individual images physically impact on an observer and the manner in which perception of them is mediated through the human body itself, either at rest, or in movement. It is this last point I will expand on here.

The images themselves, according to their specific arrangement on the rock surface, clearly perform work. They exert an agency through the body that must look down, look up, move among them, or view them at a distance, walk to the right or to the left, turn and so on. They may also, to various degrees, exert a purely visual fascination and power by drawing in and transfixing vision, acting as 'traps' (see Gell 1998). Moving around, between and over the decorated rocks always involves an encounter with image fields of different densities and intensities: those that hold attention, and those that only require a glance, those that make you stand still and those that demand changes of position and posture. There is thus a theatrical and performative element to the power of these images in terms of the degree of attention they hold and the experience of their encounter. We can thus discuss these images and the powerful effects they have on an observer's body entirely without recourse to a traditional emphasis on intentionality and meaning. Furthermore we can compare and contrast the different bodily effects of images on different rocks: on this rock I must move along it in a linear fashion in order to see them, on another rock I must move around the images in a circular motion and so on. This is important because 
part of the reception, and therefore the significance of the images, was how they are perceived by an observer. Whether the effects these images have on our bodily reception of them was discursively intended by the rock carver(s) or an unintended consequence of their action(s) is something that we can then go on to discuss. What is important here is that we can describe and discuss the bodily effects of the images in an adequate fashion entirely without needing to make reference to specific intentions in the mind of the rock carver with regard to the meaning of the imagery (e.g. the circle cross was a sun symbol).

Similarly, we can describe the bodily effects of rocks, hills, monuments, etc., and their relationships in the landscape, without recourse to a traditional notion of intentionality and meaning. My answer then to the question under debate 'can archaeology recover past intentions?' is that we can indeed do this from a phenomenological perspective stressing embodiment, but not from a traditional cognitive viewpoint demanding that we interpret what things mean or connote.

$$
\begin{array}{r}
\text { Christopher Tilley } \\
\text { Department of Anthropology } \\
\text { University College London } \\
\text { 33-35 Torrington Place } \\
\text { London } \\
\text { WC1E 6BT } \\
\text { UK } \\
\text { Email: c.tilley@ucl.ac.uk }
\end{array}
$$

\section{References}

Gell, A., 1998. Art and Agency. Oxford: Clarendon Press.

Tilley, C., 1999. Metaphor and Material Culture. Oxford: Blackwell.

Tilley, C., 2004. The Materiality of Stone: Explorations in Landscape Phenomenology. Oxford: Berg.

Tilley, C., n.d. The Agency of Imagery: Explorations in Landscape Phenomenology 2 (manuscript in preparation).

\section{Author biography}

Christopher Tilley is Professor of Anthropology at University College London. Recent books include The Materiality of Stone: Explorations in Landscape Phenomenology (2004), Metaphor and Material Culture (1999), The Dolmens and Passage Graves of Sweden (1999) and An Ethnography of the Neolithic (1996). He is currently researching two further volumes of a trilogy of books on Landscape Phenomenology and an ethnography concerned with gardens and gardening. 